\title{
Role of melatonin in the treatment of COVID-19; as an adjuvant through cluster differentiation 147 (CD147)
}

\author{
Ahmet Ozer Sehirli ${ }^{1}$ (D) Serkan Sayiner ${ }^{2}$ (D) Nedime Serakinci $^{3,4}$ (D) \\ Received: 25 June 2020 / Revised: 2 September 2020 / Accepted: 7 September 2020 / Published online: 12 September 2020 \\ (c) Springer Nature B.V. 2020
}

\begin{abstract}
COVID-19 caused by the SARS-CoV-2 outbreak quickly has turned into a pandemic. However, no specific antiviral agent is yet available. In this communication, we aimed to evaluate the significance of CD147 protein and the potential protective effect of melatonin that is mediated by this protein in COVID-19. CD147 is a glycoprotein that is responsible for the cytokine storm in the lungs through the mediation of viral invasion. Melatonin use previously was shown to reduce cardiac damage by blocking the CD147 activity. Hence, melatonin, a safe drug, may prevent severe symptoms, reduce symptom severity and the adverse effects of the other antiviral drugs in COVID-19 patients. In conclusion, the use of melatonin, which is reduced in the elderly and immune-compromised patients, should be considered as an adjuvant through its CD147 suppressor and immunomodulatory effect.
\end{abstract}

Keywords SARS-CoV-2 $\cdot$ COVID-19 $\cdot$ CD147 $\cdot$ Melatonin $\cdot$ Immunomodulator

\section{Background}

Coronaviruses (CoVs) are RNA viruses, which affect the respiratory, gastrointestinal and central nervous system, and may infect both humans and animals $[1,2]$. In recent years, the coronavirus subtypes, SARS and MERS, through their contagiousness have led to the deaths of thousands of people. The current epidemic, namely, COVID-19 discovered in Wuhan, China, has become a global pandemic in a relatively

Ahmet Ozer Sehirli

ahmetozer.sehirli@neu.edu.tr

$\triangle$ Serkan Sayiner

serkan.sayiner@neu.edu.tr

$\triangle$ Nedime Serakinci

nedime.serakinci@neu.edu.tr

1 Department of Pharmacology, Faculty of Dentistry, Near East University, Nicosia, Cyprus

2 Department of Biochemistry, Faculty of Veterinary Medicine, Near East University, Near East Boulevard, 99138 Nicosia, Cyprus

3 Department of Medical Genetics, Faculty of Medicine, Near East University, Nicosia, Cyprus

4 Department of Molecular Biology and Genetics, Faculty of Arts and Sciences, Near East University, Near East Boulevard, 99138 Nicosia, Cyprus short period. Despite the use of antiviral, anti-malarial, corticosteroid treatments and mechanical respiratory support, no specific treatment has been found for COVID-19, and mortality rates remain high, particularly in the elderly section of society [3].

\section{CD147 and coronavirus}

CoVs have been reported as non-segmented RNA viruses. CoVs leads to enzootic infections, particularly in birds and mammals, and are highly fatal in humans [4]. These viruses carry four known structural proteins; envelope (E), nucleocapsid (N), membrane (M) and spike (S) proteins. [5]. The $S$ protein is the critical constituent during the cellular invasion of SARS-CoV-2 [6]. Angiotensin-converting enzyme 2 is the host cellular receptor (ACE2) for SARS-CoV-2 and expressed in different tissues [7-10]. The interaction of $\mathrm{S}$ protein and ACE2 contributes to SARS-CoV-2 invasion of host cells [11]. Direct interactions have been demonstrated between SARS-CoV-2 and CD147 [2, 12], which is a type I transmembrane protein from the immune-globulin superfamily that plays a role in tumour development, plasmodium invasion and viral infection [13]. In lung diseases, ACE2 and CD147 increase the vascular permeability and pulmonary edema, activate the 
renin-angiotensin-aldosterone system (RAAS) and contribute to the pathogenesis of severe lung damage [13]. Studies confirm that HEK293 expressing CD147 bind with high affinity to SARS-CoV-2, thus demonstrating the importance of CD147 in the host cells [14].

CD147 (Cluster of differentiation 147) is synthesized in various cell types and widely distributed to different tissues including lungs, brain, liver, spleen, intestines and the kidneys [15]. CD147 binds to certain receptors and ligands, including S100A9, mono-carboxylate carrier (MCT)-1 and MCT-4, CD98, CD44, CD43, glycoprotein VI (GPVI), E-selectin, apolipoprotein D (ApoD), CyP60, Annexin-2 and NOD2, Caveolin-1, syndecan-1 and also integrin $\alpha 3 \beta 1$ and $\alpha 6 \beta 1$ [16-19]. Targeting CD147 have been shown to reduce inflammation and severity of the disease by affecting these ligands in asthmatic pulmonary inflammation, multiple sclerosis and myocardial ischemia/reperfusion injury [20-22]. Previous studies have noted that the expression of CD147 increases matrix metalloproteinase (MMP) activity, which is induced by MAPKs-bound Angiotensin II [23-25]. Additionally, CD147 plays a role in inflammation that develops through pro-inflammatory cytokines, including interleukin-6 (IL6 ), interferon-gamma (IFN- $\gamma$ ), tumor-necrosis factor- $\alpha$ (TNF- $\alpha$ ), and monocyte chemo-attractant protein-1 (MCP1) [26]. In most recent studies it has been suggested that SARS-CoV-2 infection stimulates the increased expression in these cytokines, which is referred to as a cytokine storm, and it is critical in disease progression [27, 28]. The cytokine storm, also referred to as hypercytokinemia, is an uncontrolled cytokine release that has been seen in some infectious and noninfectious diseases, prompting a hyper-inflammatory condition in the host [29].

The emergence and rapid spread of SARS-CoV-2 has highlighted the importance of reorganizing a global health system. Abnormal chest tomography findings are seen together with cough, fever and fatigue in COVID-19 patients [30]. Middle-aged and elderly patients who have concurrent illness have increased susceptibility to respiratory failure, with a poorer prognosis [31]. It has been stated that CD147 is involved in COVID-19 symptoms by being extremely expressed in tumor, inflammatory and infected cells [32, 33]. Thus, a drug that will target CD147 could prevent the virus from invading host cells. Hence, inhibiting the viral replication and limiting the overexpression is vitally important in COVID-19 treatment. In relation to this, CD147 antibody, Meplazumab, has been tried, and despite having achieved positive results, its administration via the parenteral route, non-availability in the market and having insufficient knowledge regarding its interaction with other antiviral drugs, have limited its widespread use [2].

\section{The effect of melatonin on immune and antioxidant systems}

The pineal gland is a neurochemical converter perceiving environmental information that can be integrated with the secretion of various biomolecules such as 5-methoxytryptophol, $\mathrm{N}$-acetylserotonin, $\mathrm{N}$-acetyltryptamine that work best with melatonin ( $\mathrm{N}$-acetyl-5-Methoxytryptamine). These secreted biomolecules have a function in the synchronization of the circadian and seasonal timing of various behavioural and physiological processes [34]. The melatonin rhythm is a powerful and vital message from suprachiasmatic nucleus signalling in order to maintain the circadian rhythm of the organism [35].

Melatonin is also a strong hydroxyl radical scavenger that protects cells from oxidative damage [36]. Besides, melatonin scavenges peroxyl radicals during lipid peroxidation $[37,38]$ and enhance the activity of antioxidant enzymes such as glutathione [39]. In light of the examples mentioned above, melatonin shows to be a crucial compound of the antioxidative system [40-42]. Indole initiates an increase in the immune response bound to T-helper cells [43]. Various immune functions, including the anti-tumorigenic defence and the cytotoxicity of natural killers, are seen to be modulated by melatonin [44]. Besides, exogenous melatonin administration has been shown to increase antibody production [45]. Thus, melatonin has immunomodulatory effects under physiological and pathophysiological conditions [46]. Notably, in cases where the immune system is suppressed, it shows an immunostimulant effect, and in cases of inflammation, it exhibits an immunosuppressive effect. It achieves its immunostimulant effect by increasing $\mathrm{T}$ cell activation, lymphocyte growth and humoral response. It shows its immunosuppressive effect by decreasing active iNOS and nNOS activities during inflammation, inhibiting COX-2, and preventing Toll-Like receptor-4 activation [47, 48]. In addition to its anti-inflammatory and pro-inflammatory effects, melatonin, unlike other modulators, has other very beneficial properties, such as antidepressant, anxiolytic, neuroprotective and antihypertensive effects [49].

\section{The antiviral effect of melatonin through CD147}

Viral infections are usually related to immunity-inflammatory damage, which includes a significantly increased oxidative stress level and adverse effects on multiple organs [50]. Melatonin does not have viricidal properties; however, it has indirect antiviral effects through 


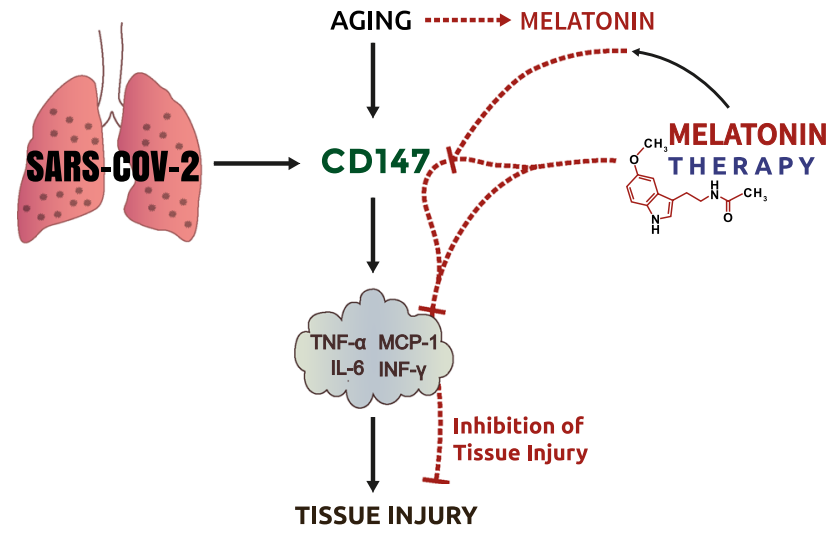

Fig. 1 SARS-CoV-2 causes tissue damage by increasing TNF- $\alpha$, MCP-1, Il-6 and INF- $\gamma$ levels through CD147. Due to both the excess of CD147 levels and the decrease in melatonin levels in elder people, tissue damage is more severe with cytokine storm. Melatonin therapy may have the ability to inhibit tissue damage by causing a decrease in CD 147 levels and thus cytokine levels

anti-inflammatory, antioxidant and immunity-enhancing effects [51]. Previously, melatonin was been shown to suppress the features of viral infections [50, 52]. Melatonin use was seen to reduce virus-mediated stroke and death, and the potency of the virus by modulating the IL- 2 and IFN- $\gamma$ concentrations during Venezuela equine encephalomyelitis (VEE) virus infection in mice [53]. Melatonin has also been reported to reduce acute lung damage in respiratory syncytial virus models, through the inhibition of oxidative damage and pro-inflammatory cytokine release. Current studies have reported that SARS-CoV-2 invades the host cells through a CD147 S protein [2]. To date, no studies have reported the influence of melatonin on CD147 $\mathrm{S}$ protein in COVID-19 patients. However, melatonin was demonstrated to possess a protective effect through the inhibition of CD147 signalling pathway via its antioxidant effects in AngII-induced cardiac hypertrophy models [54] (Fig. 1).

The processes that prevent the free radical formation as a result of exposure to stress, viral infections or toxic agents lead to a decrease the melatonin levels in older age and under suppressed immune system conditions [36, 55]. This could be part of the explanation for the poor prognosis and respiratory system failure seen in many middle-aged and elderly patients. Despite the absence of studies investigating melatonin use in COVID-19 patients, melatonin administration has yielded promising outcomes through suppressing the circulating cytokine levels in other diseases and in cases with elevated inflammation levels $[51,56,57]$. Melatonin was shown to stimulate a significant decline in serum MMP, TNF- $\alpha$, IFN- $\gamma$, IL-6, MCP- 1 and C-reactive protein (CRP) levels in experimental and clinical studies $[58,59]$. These mediators are known to have a critical role in CD147-mediated inflammation pathway. Melatonin has also been reported to have an anti-diabetic effect. Evidence from experimental studies show that melatonin induces insulin growth factor synthesis and promotes insulin receptor tyrosine phosphorylation. Disruption of the internal circadian system causes glucose intolerance and insulin resistance, and this can be restored with melatonin administration [60-62]. Further, melatonin administration has been proven to reduced cellular apoptosis and promote antioxidants in diabetes [63]. Thus, it is suggested that CD147 may play a role in the emergence of these effects of melatonin in diabetic patients with COVID-19.

The safety of melatonin administration is of vital importance when its use is suggested for treating COVID-19. Previously, short-term administration of melatonin has shown to be secure even when used at relatively high doses [64, 65]. Additionally, the use of melatonin, together with other drugs in COVID-19 treatment, was shown to increase their potency and reduce their side effect potential [66].

\section{Conclusion}

One could speculate that melatonin may be a candidate drug to provide relief from the clinical symptoms of COVID19 even though its antioxidant effect cannot eliminate or stop the viral replication or transcription. Together with ACE2, CD147 has a vital role in the activation pathway of COVID-19. It could be suggested that the possible reason for the greater impact of COVID-19 on the elderly part of populations is both related to reduced melatonin levels and increased CD147 levels. Thus, in light of current literature and the above discussion, we suggest that the use of melatonin in combination with antiviral agents could yield more effective outcomes through its CD147 suppressor effect, immune-modulatory effect and reducing the potential negative side effects of antiviral agents.

Author contributions AOS, SS and NS had the idea for the article, performed literature search and data analysis. AOS and SS drafted the article and NS critically revised the article.

Funding Not applicable.

\section{References}

1. Malik YS, Sircar S, Bhat $S$ et al (2020) Emerging novel coronavirus (2019-nCoV)-current scenario, evolutionary perspective based on genome analysis and recent developments. Vet Q 40:68-76. https://doi.org/10.1080/01652176.2020.1727993

2. Wang K, Chen W, Zhou Y-S et al (2020) SARS-CoV-2 invades host cells via a novel route: CD147-spike protein. bioRxiv. https ://doi.org/10.1101/2020.03.14.988345 
3. Huang C, Wang Y, Li X et al (2020) Clinical features of patients infected with 2019 novel coronavirus in Wuhan, China. Lancet 395:497-506. https://doi.org/10.1016/S0140-6736(20)30183-5

4. Wang W, Xu Y, Gao R et al (2020) Detection of SARS-CoV-2 in different types of clinical specimens. JAMA 323:1843-1844. https ://doi.org/10.1001/jama.2020.3786

5. Rota PA, Oberste MS, Monroe SS et al (2003) Characterization of a novel coronavirus associated with severe acute respiratory syndrome. Science 300:1394-1399. https://doi.org/10.1126/scien ce. 1085952

6. Hulswit RJG, de Haan CAM, Bosch B-J (2016) Coronavirus spike protein and tropism changes. Adv Virus Res 96:29-57. https://doi. org/10.1016/bs.aivir.2016.08.004

7. Donoghue M, Hsieh F, Baronas E et al (2000) A novel angiotensin-converting enzyme-related carboxypeptidase (ACE2) converts angiotensin I to angiotensin 1-9. Circ Res 87:E1-E9. https://doi. org/10.1161/01.res.87.5.e1

8. Harmer D, Gilbert M, Borman R, Clark KL (2002) Quantitative mRNA expression profiling of ACE 2, a novel homologue of angiotensin converting enzyme. FEBS Lett 532:107-110. https ://doi.org/10.1016/s0014-5793(02)03640-2

9. Hamming I, Timens W, Bulthuis MLC et al (2004) Tissue distribution of ACE2 protein, the functional receptor for SARS coronavirus. A first step in understanding SARS pathogenesis. J Pathol 203:631-637. https://doi.org/10.1002/path.1570

10. Jia HP, Look DC, Shi L et al (2005) ACE2 receptor expression and severe acute respiratory syndrome coronavirus infection depend on differentiation of human airway epithelia. J Virol 79:14614 14621. https://doi.org/10.1128/JVI.79.23.14614-14621.2005

11. Mathewson AC, Bishop A, Yao Y et al (2008) Interaction of severe acute respiratory syndrome-coronavirus and NL63 coronavirus spike proteins with angiotensin converting enzyme-2. J Gen Virol 89:2741-2745. https://doi.org/10.1099/vir.0.2008/003962-0

12. Ulrich H, Pillat MM (2020) CD147 as a target for COVID-19 treatment: suggested effects of azithromycin and stem cell engagement. Stem cell Rev reports 16:434-440. https://doi.org/10.1007/ s12015-020-09976-7

13. Kuba K, Imai Y, Ohto-Nakanishi T, Penninger JM (2010) Trilogy of ACE2: a peptidase in the renin-angiotensin system, a SARS receptor, and a partner for amino acid transporters. Pharmacol Ther 128:119-128. https://doi.org/10.1016/j.pharmthera .2010 .06 .003

14. Chen Z, Mi L, Xu J et al (2005) Function of HAb18G/CD147 in invasion of host cells by severe acute respiratory syndrome coronavirus. J Infect Dis 191:755-760. https://doi.org/10.1086/42781 1

15. Miyauchi T, Kanekura T, Yamaoka A et al (1990) Basigin, a new, broadly distributed member of the immunoglobulin superfamily, has strong homology with both the immunoglobulin V domain and the beta-chain of major histocompatibility complex class II antigen. J Biochem 107:316-323. https://doi.org/10.1093/oxfor djournals.jbchem.a123045

16. Kirk P, Wilson MC, Heddle C et al (2000) CD147 is tightly associated with lactate transporters MCT1 and MCT4 and facilitates their cell surface expression. EMBO J 19:3896-3904. https://doi. org/10.1093/emboj/19.15.3896

17. Yurchenko V, O'Connor M, Dai WW et al (2001) CD147 is a signaling receptor for cyclophilin B. Biochem Biophys Res Commun 288:786-788. https://doi.org/10.1006/bbrc.2001.5847

18. Slomiany MG, Dai L, Tolliver LB et al (2009) Inhibition of functional hyaluronan-CD44 interactions in CD133-positive primary human ovarian carcinoma cells by small hyaluronan oligosaccharides. Clin Cancer Res 15:7593-7601. https://doi. org/10.1158/1078-0432.CCR-09-2317

19. Hibino T, Sakaguchi M, Miyamoto S et al (2013) S100A9 is a novel ligand of EMMPRIN that promotes melanoma metastasis.
Cancer Res 73:172-183. https://doi.org/10.1158/0008-5472. CAN-11-3843

20. Marchiq I, Albrengues J, Granja S et al (2015) Knock out of the BASIGIN/CD147 chaperone of lactate/H+ symporters disproves its pro-tumour action via extracellular matrix metalloproteases (MMPs) induction. Oncotarget 6:24636-24648. https ://doi.org/10.18632/oncotarget.4323

21. Xiong L, Edwards CK 3rd, Zhou L (2014) The biological function and clinical utilization of CD147 in human diseases: a review of the current scientific literature. Int J Mol Sci 15:17411-17441. https://doi.org/10.3390/ijms151017411

22. Wang C-H, Dai J-Y, Wang L et al (2011) Expression of CD147 (EMMPRIN) on neutrophils in rheumatoid arthritis enhances chemotaxis, matrix metalloproteinase production and invasiveness of synoviocytes. J Cell Mol Med 15:850-860. https://doi. org/10.1111/j.1582-4934.2010.01084.x

23. Bukrinsky M (2015) Extracellular cyclophilins in health and disease. Biochim Biophys Acta 1850:2087-2095. https://doi. org/10.1016/j.bbagen.2014.11.013

24. Li J, Huang Q, Long X et al (2015) CD147 reprograms fatty acid metabolism in hepatocellular carcinoma cells through Akt/ mTOR/SREBP1c and P38/PPARalpha pathways. J Hepatol 63:1378-1389. https://doi.org/10.1016/j.jhep.2015.07.039

25. Yu Q, Yang D, Chen X, Chen Q (2019) CD147 increases mucus secretion induced by cigarette smoke in COPD. BMC Pulm Med 19:29. https://doi.org/10.1186/s12890-019-0791-0

26. Zhai Y, Wu B, Li J et al (2016) CD147 promotes IKK/Ikap$\mathrm{paB} / \mathrm{NF}-\mathrm{kappaB}$ pathway to resist TNF-induced apoptosis in rheumatoid arthritis synovial fibroblasts. J Mol Med (Berl) 94:71-82. https://doi.org/10.1007/s00109-015-1334-7

27. Saghazadeh A, Rezaei N (2020) Immune-epidemiological parameters of the novel coronavirus-a perspective. Expert Rev Clin Immunol 16:465-470. https://doi.org/10.1080/17446 66X.2020.1750954

28. Liu Y, Yan L-M, Wan L et al (2020) Viral dynamics in mild and severe cases of COVID-19. Lancet Infect Dis 20:656-657. https ://doi.org/10.1016/S1473-3099(20)30232-2

29. Mahmudpour M, Roozbeh J, Keshavarz M et al (2020) COVID19 cytokine storm: the anger of inflammation. Cytokine 133:155151. https://doi.org/10.1016/j.cyto.2020.155151

30. Lai S, Ruktanonchai NW, Zhou L et al (2020) Effect of nonpharmaceutical interventions to contain COVID-19 in China. Nature. https://doi.org/10.1038/s41586-020-2293-x

31. Gorbalenya AE, Baker SC, Baric RS et al (2020) The species severe acute respiratory syndrome-related coronavirus: classifying 2019-nCoV and naming it SARS-CoV-2. Nat Microbiol 5:536-544. https://doi.org/10.1038/s41564-020-0695-z

32. Chen J, Peng C, Lei L et al (2017) Nuclear envelope-distributed CD147 interacts with and inhibits the transcriptional function of RING1 and promotes melanoma cell motility. PLoS ONE 12:e0183689. https://doi.org/10.1371/journal.pone.0183689

33. Cui J, Huang W, Wu B et al (2018) N-glycosylation by N-acetylglucosaminyltransferase V enhances the interaction of CD147/ basigin with integrin $\beta 1$ and promotes HCC metastasis. J Pathol 245:41-52. https://doi.org/10.1002/path.5054

34. Bonmati-Carrion MA, Arguelles-Prieto R, Martinez-Madrid MJ et al (2014) Protecting the melatonin rhythm through circadian healthy light exposure. Int J Mol Sci 15:23448-23500. https:// doi.org/10.3390/ijms 151223448

35. Felder-Schmittbuhl M-P, Buhr ED, Dkhissi-Benyahya O et al (2018) Ocular clocks: adapting mechanisms for eye functions and health. Invest Ophthalmol Vis Sci 59:4856-4870. https:// doi.org/10.1167/iovs.18-24957

36. Reiter RJ, Tan DX, Rosales-Corral S et al (2018) Mitochondria: central organelles for melatonin's antioxidant and anti-aging 
actions. Molecules 23:509. https://doi.org/10.3390/molecules2 3020509

37. Sener G, Sehirli AO, Paskaloglu K et al (2003) Melatonin treatment protects against ischemia/reperfusion-induced functional and biochemical changes in rat urinary bladder. J Pineal Res 34:226230. https://doi.org/10.1034/j.1600-079x.2003.00038.x

38. Sehirli AO, Koyun D, Tetik S et al (2013) Melatonin protects against ischemic heart failure in rats. J Pineal Res 55:138-148. https://doi.org/10.1111/jpi.12054

39. Alghamdi BS (2018) The neuroprotective role of melatonin in neurological disorders. J Neurosci Res 96:1136-1149. https://doi. org/10.1002/jnr.24220

40. Akyuz C, Yasar NF, Uzun O et al (2018) Effects of melatonin on colonic anastomosis healing following chemotherapy in rats. Singapore Med J 59:545-549. https://doi.org/10.11622/smedj.20180 35

41. Sener G, Sehirli AO, Satiroglu H et al (2002) Melatonin prevents oxidative kidney damage in a rat model of thermal injury. Life Sci 70:2977-2985. https://doi.org/10.1016/s0024-3205(02)01571-0

42. Cetinel S, Ercan F, Sirvanci S et al (2003) The ameliorating effect of melatonin on protamine sulfate induced bladder injury and its relationship to interstitial cystitis. J Urol 169:1564-1568. https:// doi.org/10.1097/01.ju.0000049649.80549.17

43. Alvarez-Sanchez N, Cruz-Chamorro I, Diaz-Sanchez M et al (2017) Melatonin reduces inflammatory response in peripheral $\mathrm{T}$ helper lymphocytes from relapsing-remitting multiple sclerosis patients. J Pineal Res 63:e12442. https://doi.org/10.1111/ jpi.12442

44. Mortazavi M, Salehi I, Alizadeh Z et al (2014) Protective effects of antioxidants on sperm parameters and seminiferous tubules epithelium in high fat-fed rats. J Reprod Infertil 15:22-28

45. Perfilyeva YV, Ostapchuk YO, Abdolla N et al (2019) Exogenous melatonin up-regulates expression of CD62L by lymphocytes in aged mice under inflammatory and non-inflammatory conditions. Immunol Invest 48:632-643. https://doi.org/10.1080/08820 139.2019.1586918

46. Hardeland R (2019) Melatonin and chromatin. Melatonin Res 2:67-93. https://doi.org/10.32794/mr11250012

47. Carrillo-Vico A, Lardone PJ, Álvarez-Śnchez N et al (2013) Melatonin: buffering the immune system. Int J Mol Sci 14:8638-8683. https://doi.org/10.3390/ijms14048638

48. Nabavi SM, Nabavi SF, Sureda A et al (2019) Anti-inflammatory effects of melatonin: a mechanistic review. Crit Rev Food Sci Nutr 59:S4-S16. https://doi.org/10.1080/10408398.2018.1487927

49. Emet M, Ozcan H, Ozel L et al (2016) A review of melatonin, its receptors and drugs. Eurasian J Med 48:135-141. https://doi. org/10.5152/eurasianjmed.2015.0267

50. Lu R, Liu Z, Shao Y et al (2019) Melatonin is responsible for rice resistance to rice stripe virus infection through a nitric oxidedependent pathway. Virol J 16:141. https://doi.org/10.1186/s1298 5-019-1228-3

51. Zhang R, Wang X, Ni L et al (2020) COVID-19: melatonin as a potential adjuvant treatment. Life Sci 250:117583. https://doi. org/10.1016/j.lfs.2020.117583

52. Bonilla E, Valero N, Chacin-Bonilla L, Medina-Leendertz S (2004) Melatonin and viral infections. J Pineal Res 36:73-79. https://doi.org/10.1046/j.1600-079x.2003.00105.x

53. Negrette B, Bonilla E, Valero N et al (2001) Melatonin treatment enhances the efficiency of mice immunization with venezuelan equine encephalomyelitis virus TC-83. Neurochem Res 26:767770. https://doi.org/10.1023/a:1011645400123

54. Su H, Li J, Chen T et al (2016) Melatonin attenuates angiotensin II-induced cardiomyocyte hypertrophy through the CyPA/CD147 signaling pathway. Mol Cell Biochem 422:85-95. https://doi. org/10.1007/s11010-016-2808-9

55. Lee F-Y, Sun C-K, Sung P-H et al (2018) Daily melatonin protects the endothelial lineage and functional integrity against the aging process, oxidative stress, and toxic environment and restores blood flow in critical limb ischemia area in mice. J Pineal Res 65:e12489. https://doi.org/10.1111/jpi.12489

56. Zhou F, Yu T, Du R et al (2020) Clinical course and risk factors for mortality of adult inpatients with COVID-19 in Wuhan, China: a retrospective cohort study. Lancet 395:1054-1062. https://doi. org/10.1016/S0140-6736(20)30566-3

57. Shneider A, Kudriavtsev A, Vakhrusheva A (2020) Can melatonin reduce the severity of COVID-19 pandemic? Int Rev Immunol 39:153-162. https://doi.org/10.1080/08830185.2020.1756284

58. Savtekin G, Serakinci N, Erzik C et al (2018) Effects of circadian rhythm hormones melatonin and 5-methoxytryptophol on COXs, Raf-1 and STAT3. Int J Pharmacol 14:787-795. https:// doi.org/10.3923/ijp.2018.787.795

59. Farias TSM, da de, Paixao RI, Cruz MM et al (2019) Melatonin supplementation attenuates the pro-inflammatory adipokines expression in visceral fat from obese mice induced by a high-fat diet. Cells 8:1041. https://doi.org/10.3390/cells8091041

60. Sharma S, Singh H, Ahmad N et al (2015) The role of melatonin in diabetes: therapeutic implications. Arch Endocrinol Metab 59:391-399. https://doi.org/10.1590/2359-3997000000098

61. Karamitri A, Jockers R (2019) Melatonin in type 2 diabetes mellitus and obesity. Nat Rev Endocrinol 15:105-125. https://doi. org/10.1038/s41574-018-0130-1

62. Song J, Whitcomb DJ, Kim BC (2017) The role of melatonin in the onset and progression of type 3 diabetes. Mol Brain 10:35. https://doi.org/10.1186/s13041-017-0315-x

63. Mok JX, Ooi JH, Ng KY et al (2019) A new prospective on the role of melatonin in diabetes and its complications. Horm Mol Biol Clin Investig. https://doi.org/10.1515/hmbci-2019-0036

64. Kucukakin B, Lykkesfeldt J, Nielsen HJ et al (2008) Utility of melatonin to treat surgical stress after major vascular surgery-a safety study. J Pineal Res 44:426-431. https://doi.org/10.1111/ j.1600-079X.2007.00545.x

65. Sanchez-Lopez AL, Ortiz GG, Pacheco-Moises FP et al (2018) Efficacy of melatonin on serum pro-inflammatory cytokines and oxidative stress markers in relapsing remitting multiple sclerosis. Arch Med Res 49:391-398. https://doi.org/10.1016/j.arcme d.2018.12.004

66. Adikwu E, Ebinyo NC, Bokolo B (2020) Melatonin and alpha lipoic acid attenuate methotrexate/cisplatin-induced kidney toxicity in albino rats. J Nephropharmacol 9:e17. https://doi. org/10.15171/npj.2020.17

Publisher's Note Springer Nature remains neutral with regard to jurisdictional claims in published maps and institutional affiliations. 